\title{
Three new taxa of Lepista: L. fasciculata n. sp., L. singeri n. sp. and Lepista subgenus Laevispora n. subg.
}

\author{
Harri Harmaja \\ Botanical Museum, University of Helsinki, SF-00170 Helsinki, Finland
}

\begin{abstract}
Harmaja, H. 1974: Three new taxa of Lepista: L. fasciculata n. sp., L. singeri n. sp. and Lepista subgenus Laevispora n. subg. - Karstenia 14: 129-132.

The author describes two new species of Lepista (Fr.) W. G. Smith sensu Harmaja 1974 (Agaricales). Lepista fasciculata Harmaja differs from the apparently closely related L. subalpina (Big. \& Smith) Harmaja mainly through its paler, non-hygrophanous pileus and somewhat larger spores. Lepista singeri Harmaja differs from the closely related $L$. (Clitocybe) nebularis (Fr.) Harmaja in the tricholomoid habit with sinuate gill-attachment, much paler colour of the pileus without grey tinges, and a larger hilar appendix of the spore. From L. irina (Fr.) Bigelow it differs above all through the perfectly smooth spores under the light microscope, the different odour, and probably also through a yellowish spore colour. L. singeri appears to be the »Tricholoma irinum with smooth not reddish spores» of some authors. New and more accurate details of the characters of this species are given. The new subgenus Lepista subg. Laevispora Harmaja is established to accommodate the two species, $L$. nebularis (as the type) and $L$. singeri, which have all their spores completely smooth under the light microscope, a yellow spore colour (not quite certain in L. singeri), and a characteristic common odour. In subg. Lepista all the spores are warted (however, in one species a part of even mature spores are smooth), the spore deposit is reddish, and the odours are different.
\end{abstract}

\section{Lepista fasciculata n. sp.}

Lepista fasciculata Harmaja, n. sp. A Lepista subalpina (Big. E Smith) Harmaja pileo non hygrophano, colore pilei dissimiti et sporis grandioribus differt. - Type: Finland, prov. Varsinais-Suomi, Lohja, Ojamo, Porla, in a grass-herb mixed forest with $\mathrm{Be}$ tula alba, Picea abies etc., the character of which has been influenced by human activities, on fertile somewhat calcareous soil, a dense fascicle at the base of a tree-stump; among others, the following plant species, indicators of fertile soils, grow in the immediate neighbourhood: Carex remota, $C$. tumidicarpa, Galium odoratum (unless extinct), Epilobium obscurum, Mercurialis perennis, Poa remota, Eurhynchium angustirete and Mnium undulatum; 1967-11-02,
Harri Harmaja (H).

Pileus at least reaching a diameter of 7.5 $\mathrm{cm}$, not hygrophanous, not pruinose, rather pale brown (when dry near 12 C 6 in Maerz \& Paul 1950), \pm plane with somewhat undulating margin which is inrolled for a rather long time; surface dry (not slimy or viscid), smooth and glabrous, somewhat shining when dry.

Stipe ca. 8-10 $\times 1-2 \mathrm{~cm}$, much paler than pileus being whitish with a brownish tint, enlarged downwards; surface dry, almost glabrous; very scanty whitish hyphal tomentum present at the base; the stipe bases \pm connate resulting to a densely fasciculate manner of growth.

Lamellae short decurrent (not sinuate at 
all), concolorous with pileus or slightly paler, close, rather thin, narrow.

Odour not distinct (»fungoid»).

Taste mild in both fresh and dried fruit bodies.

Spores (in Melzer's unless otherwise stated) $5.0-6.5 \times 3.0-4.0 \mu \mathrm{m}$; the majority of detached spores adher together in tetrads and dyads in mounts of dried gills; a considerable proportion of the spores, especially the immature ones mostly still attached to the sterigmata, with more or less collapsed walls (and then almost or completely without contents) in mounts of dried gills; all obtusebased; all ellipsoid; plage applanated, smooth; wall ca. $0.3 \mu \mathrm{m}$ thick, verruculose with rather scattered warts which become more densely situated and larger towards the spore apex (in fact, in some spores the lower half is smooth) and which are sometimes connected in places to form a delicate reticulum, inamyloid, indextrinoid, strongly cyanophilic including the warts; hilar appendix ca. $0.7-0.8 \times 0.5-0.6 \mu \mathrm{m}$, truncate, slightly tapering towards apex, with a cyanophobic wall; contents possibly weakly cyanophilic, with one large oil drop or several small ones; spore deposit pale pinkish buff, approximately 9 B 2 in MAERz \& PaUL 1950.

Basidia ca. $22-28 \times 5.0-6.5 \mu \mathrm{m}$, fourspored, all with inamyloid, indextrinoid and cyanophobic walls.

Cystidia of any kind absent.

Hymenophoral trama regular.
Epicutis ca. 50-100 $\mu \mathrm{m}$ thick, its hyphae rather interwoven to subparallel, $2.0-4.0$ $\mu \mathrm{m}$ in diameter, with abundant hyaline (in $5 \% \mathrm{KOH}$ ) slightly light-refractive contents, in places with wrinkled walls, no kind of pigment observed; subcutis indistinct, ca. $100-200 \mu \mathrm{m}$ thick, hyphae subparallel, 2.5$7.0 \mu \mathrm{m}$ in diameter, the hyphal walls seem to be very pale brown, i.e. possess scanty (intra)membranal pigment; small clamp connections abundant, apparently present at each septum.

Macrochemical tests: Potassium hydroxide ( $5 \%$ ): negative on pileus surface, stipe surface, lamellae and context (all dried). Aniline oil: no reaction at least within five minutes on fresh pileus surface and fresh lamellae. - Ferrous sulphate: negative on fresh lamellae.

Macroscopically this species very much resembles Lyophyllum decastes (Fr.) Sing. but there are no difficulties in placing it to Lepista (Fr.) W. G. Smith when the microscope is used. L. subalpina (Big. \& Smith) Harmaja has certain characters in common with $L$. fasciculata, but differs from the latter in the features of its pileus which is hygrophanous and slightly darker displaying a different shade of brown, and in the slightly smaller spores which measure about $4.5-5.5$ $\times 3.0-4.0 \mu \mathrm{m}$. The scanty material of both does not allow a reasonable comparison between the ecological characters of these species.

\section{Lepista singeri n. sp.}

Lepista singeri Harmaja, n. sp. - Valde similis Lepistae nebularis (Fr.) Harmaja, sed ab ea differt habitu tricholomatoideo (lamellae sunt sinuatae), colore pallido pilei et appendice hilari sporarum grandiore. A Lepista irina (Fr.) Bigelow sporis laevibus et odore dissimili differt. - Type: Finland, prov. Varsinais-Suomi, rural district of Lohja, Hermala, near Kalkkimäki, in an incomplete fairy ring in an open place in a grazed grass-herb forest (approximately representing the OMaT site type) with Picea abies, Alnus incana and Betula alba on calcareous soil, in a mixed substrate composed of coniferous and deciduous litter and mull, 1970-10-03, Harri Harmaja ( $\mathrm{H})$.

Pileus at least up to $7 \mathrm{~cm}$ broad (most probably becoming larger), not hygrophanous, very pale when fresh but somewhat darker, cream-coloured (9 D 3 in MAERz \& Paul 1950), when dry, convex at first becoming nearly plane in age; margin distinctly inrolled for a long time; surface dry, smooth and glabrous.

Stipe ca. $6-8 \times 1-2 \mathrm{~cm}$, paler than pileus (especially in dried basidiocarps), somewhat enlarged downwards; surface dry, indistinctly mealy upwards; scanty whitish hyphal tomentum present towards the base.

Lamellae sinuate, very narrowly attached to the very top of the stipe, slightly darker than the pileus both in the fresh and dried condition, crowded, thin, and narrow.

Odour exactly as in L. (Clitocybe) nebu- 
laris, i.e., in fresh fruit bodies sweetish, resembling that of Swedish turnip, in exsiccates slightly stronger, more honey-like.

Taste mild in both fresh and dried basidiocarps.

Spores (in Melzer's unless otherwise stated) $6.0-8.5 \times 3.5-4.0 \mu \mathrm{m}$; the majority of the detached spores adher together in tetrads and dyads, i.e. clusters of four and two, in mounts of dried gills; the majority, especially the immature ones mostly still attached to the sterigmata, with more or less collapsed walls (and then almost or completely without contents) in mounts of dried gills; all obtuse-based; most ellipsoid, the rest obovoid and oblong; suprahilar area, or plage, in most spores depressed, in the rest of them applanated; wall ca. 0.3-0.4 $\mu \mathrm{m}$ thick, perfectly smooth in all spores when studied under the light microscope, even with an oil immersion lens and a magnification of 1500 $\times$, very pale yellow in water and $5 \% \mathrm{KOH}$, inamyloid, indextrinoid, strongly cyanophilic (weakly so in very young spores); hilar appendix ca. $0.7-0.8 \times 0.6-0.7 \mu \mathrm{m}$, equal, truncate, with a cyanophobic wall; contents probably weakly cyanophilic (difficult to judge because of the cyanophily of the wall), with one large and/or several small indistinct oil drops; colour of spore deposit not known, but most probably yellow (as the spores appear to possess a yellow tinge in water and $5 \% \mathrm{KOH}$ mounts, which is observed especially where there happen to be many spores together, such as in the tetrads and groups of tetrads, and when compared with the faint reddish tint of the spore clusters of e.g. Clitocybe odora on the one hand and the yellowish tint of those of $L$. nebularis on the other, prepared to the same mount for comparison).

Basidia ca. 25-32 × 5.0-6.5 $\mu \mathrm{m}$, fourspored, all with inamyloid, indextrinoid and cyanophobic walls.

Cystidia of any kind absent.

Hymenophoral trama of the regular type.

Epicutis rather weakly differentiated, ca. $150-220 \mu \mathrm{m}$ in thickness, composed of more or less parallel filamentous hyphae which are $2.0-5.0 \mu \mathrm{m}$ in diameter and get gradually wider downwards and change to the hyphae of the pileus trama; hyphal walls hyaline, inamyloid, indextrinoid and cyanophobic; intercellular, (intra)membranal and epimembranal pigments lacking, so the pale colour of the pileus surface is due to scanty intracellular pigment; clamp connections abundant, apparently present at each septum. A subcutis not discernible.

This new species is named in the honour of Prof. Dr. Rolf Singer, Chicago, who has added so much to our knowledge of the genus Lepista. The species belongs to the genus Lepista as amended by me (Harmaja 1974), where L. nebularis (Fr.) Harmaja (Clitocybe nebularis) and it form a subgenus of their own which will be described below. $L$. singeri is thus most closely related to $L$. nebularis, from which it firstly differs in its distinctly tricholomoid habit, i.e., its gill-attachment is quite different, the lamellae being sinuate and very narrowly attached to the very top of the stipe, while the habit of $L$. nebularis is clitocyboid with decurrent gills. The second difference lies in the pigmentation, since the pileus of $L$. nebularis is normally much darker than that of L. singeri (however, the cap of certain infrequent more or less albinic forms of L. nebularis assumes in drying colours very similar to the colour of the pileus of $L$. singeri). Thirdly, the hilar appendix of the spore of $L$. singeri is slightly larger, ca. $0.7-0.8 \times 0.6-0.7 \mu \mathrm{m}$, than that of $L$. nebularis which measures ca. $0.6-0.7 \times 0.4-$ $0.5 \mu \mathrm{m}$ (Harmaja 1969). This difference may not appear distinct enough (in fact, also the structure concerned is itself extremely tiny), but, especially in view of my experience in the taxonomy of Clitocybe (HARMAJA 1969), I consider this difference significant.

From L. irina the new species differs above all through its spores, which all are perfectly smooth under the light microscope, even with high magnifications using an oil immersion lens, also appearing so when the phase contrast illumination is used, and when the spore wall is stained with cotton blue. Secondly, the spores of the new species are probably yellowish as in L. nebularis (cf. the description), while the spore mass of L. irina possesses the reddish tinge so typical of the genus Lepista. Thirdly, the odour of $L$. singeri is somewhat different and apparently less sweet, being identical with that of $L$. nebularis, including its persistence in the dry basidiocarp in a somewhat altered form (cf. the description). It is also probable that other differences exist; e.g. the pileus flesh may be thinner and the lamellae narrower in $L$. singeri. 
The new species is no doubt the $\gg$ Tricholoma irinum» of some authors, e.g. SINGER 1962 (but not later), and the obvious existence of two different species called $T$. irinum, one with reddish and verruculose, the other with »white» or whitish and smooth spores, has been discussed in the literature. On the basis of the original Friesian description of $\mathrm{Aga}$ ricus irinus Fr. one cannot with certainty tell which one he meant. However, on the basis of his remarks on the pileus surface, the stature of the fruit body and especially the odour, and my supposition that the roughspored species is more frequent in NW-Eu- rope, I prefer to agree with the leading opinion according to which the species with (partly) verruculose and reddish spores is the original $A$. irinus. The other species, that with smooth and »white or whitish» (because of too thin deposits? According to my observations the spore colour appears to be yellowish) spores is apparently undescribed which is the reason why I have prepared the formal description after having myself found this fungus. According to the current taxonomical criteria it would indeed key out among the clamped Tricholomas, but, as stated above, I would include it in Lepista.

\section{Lepista subgenus Laevispora n. subg.}

Lepista subg. Laevispora Harmaja, n. subg. - A subgenere typico (subg. Lepista) differt sporis perfecte laevibus, colore flavo sporarum (certe in typo, verisimiliter in specie alia) et odore dissimili basidiocarpi. - Type: Lepista nebularis (Fr.) Harmaja.

This new subgenus is needed in the genus Lepista as having been amended to include species with all their spores completely smooth and with a yellow spore deposit (Harmaja 1974), i.e., to accommodate $L$. nebularis and $L$. singeri. The most important differences from the type subgenus, subg. $L e$ pista, which now automatically becomes established as the genus was not divided into subgenera before, thus lie in the spores. In the subgenus Lepista they all are verruculose, or (in L. irina) at least a considerable proportion, while in the subgenus Laevispora all the spores are perfectly smooth under the light microscope. Secondly, the spore deposit of the type species of the new subgenus is deep yellow without any reddish tint (Harmaja 1969), and that of the other species, L. singeri, also appears to be yellowish rather than reddish (see the species description above). Thirdly, both the species of the subgenus Laevispora possess an identical odour, which is turnip-like in fresh fruit bodies, turning honey-like in dried ones, while this kind of odour seems to be absent in the type subgenus where species with different kinds of odour exist along with practically odourless ones. The spores in the new subgenus are fairly large, while the spore size is very variable in the subgenus Lepista.

For the moment I prefer to refrain from making any decisions concerning the sectional division of the subgenera. It appears that this division requires further clarification, including the validity of the nomenclature.

\section{REFERENCES}

Harmaja, H. 1969: The genus Clitocybe (Agaricales) in Fennoscandia. - Karstenia 10: $5-168$.

- 1974: A revision of the generic limit between Clitocybe and Lepista. - Karstenia 14: $82-92$.
Maerz, A. and Paul, M. R. 1950: A dictionary of color. $-208 \mathrm{pp}$. New York.

Singer, R. 1962: The Agaricales in modern taxonomy. 2nd ed. $-915+73$. Weinheim. 